\title{
Tourniquet use in combat-injured service members: a link with heterotopic ossification?
}

This article was published in the following Dove Press journal:

Orthopedic Research and Reviews

2I March 2014

Number of times this article has been viewed

\author{
Brad M Isaacson ${ }^{1,2}$ \\ Thomas M Swanson 1,2,4 \\ Benjamin K Potter ${ }^{4}$ \\ Paul F Pasquina ${ }^{2,3}$ \\ 'The Henry M Jackson Foundation for \\ the Advancement of Military Medicine, \\ ${ }^{2}$ The Center for Rehabilitation \\ Sciences Research, Department of \\ Physical Medicine and Rehabilitation, \\ Uniformed Services University of \\ Health Sciences, ${ }^{3}$ Department of \\ Rehabilitation, Walter Reed National \\ Military Medical Center, ${ }^{4}$ Department \\ of Orthopaedics, Walter Reed \\ National Military Medical Center, \\ Bethesda, MA, USA
}

Correspondence: Brad M Isaacson 316 Mill Street EXT, Lancaster, MA 0I523, USA

Tel + I 6I07727252

Email bmisaacson@gmail.com

\begin{abstract}
Tourniquet use during Operation Enduring Freedom (OEF) and Operation Iraqi Freedom (OIF) has contributed to the high survival rate of combat-injured service members. While preservation of a life - even at the potential expense of a limb - should always take precedence, delayed perfusion in traumatized residual limbs may alter the proliferation, differentiation, and function of endothelial and osteoprogenitor cells. Given the synergistic relationship between angiogenesis and osteogenesis, and the influence of environmental conditions on bone formation, hypoxic conditions from tourniquets may in part explain the higher frequency of heterotopic ossification (HO) present during OIF/OEF. Determining a correlation between tourniquet usage/ duration on subsequent $\mathrm{HO}$ formation remains challenging. Long-term retrospective investigations have been limited, since the United States Army's Institute of Surgical Research did not standardized tourniquet issuance until July 2004. Thus, associating tourniquet-induced HO in previous military conflicts is not feasible, since poor medical documentation and inadequate application of these medical devices prevent large-scale meta-analyses. Therefore, this article focuses on the basics of bone biology and how tourniquet usage following combat trauma may impact osteogenesis, and subsequently, ectopic bone formation.
\end{abstract}

Keywords: heterotopic ossification, osteogenesis, combat, trauma, ectopic bone, osteoprogenitor cells, Operation Iraqi Freedom, Operation Enduring Freedom

\section{Introduction}

Medical advancements in Operation Enduring Freedom (OEF) and Operation Iraqi Freedom (OIF) have led to a $92 \%$ survival rate of combat-injured service members, a higher proportion than previous military conflicts. ${ }^{1}$ Congressional databases have indicated that, as of December 2013, returning US military combatants have sustained 1,558 major limb amputations (762 from OEF and 796 from OIF/Operation New Dawn [OND]). ${ }^{2}$ Utilizing tourniquets for controlling hemorrhaging on the battlefield has contributed to this progression, as $70 \%$ of injuries sustained in OIF and OEF have been to the musculoskeletal system, ${ }^{3}$ with uncontrolled bleeding accounting for $50 \%$ of all combat fatalities. ${ }^{4}$ While preservation of a life - even at the potential expense of a limb - has always taken and should always take precedence, ${ }^{5}$ concerns about gangrene and neuromuscular damage from prolonged vascular occlusion prevented widespread acceptance of tourniquets during World War I, World War II, and the Vietnam War. ${ }^{5,6}$ However, retrospective reviews from these military conflicts have noted that approximately $7 \%-9 \%$ of battlefield deaths may have been prevented with tourniquet usage. ${ }^{4,5}$ This statistic coupled with the rapid evacuation strategies in OIF/OEF and data from the Israeli Defense Forces 
Medical Corps have demonstrated the effectiveness of tourniquets for preventing exsanguinations in the military pre-hospital setting. ${ }^{7}$ As such, each US service member is now equipped with a tourniquet.

When a tourniquet is appropriately applied and inflated to $300-400 \mathrm{mmHg}$ in theater, all arterial bleeding within the extremity ceases ${ }^{8}$ and hypoxemic conditions remain until surgical intervention is possible. In some instances, postoperative wound hypoxia may persist upon tourniquet release, due to vasoconstriction and distal microvasculature blockage from cellular debris. ${ }^{8}$ Delayed perfusion in traumatized residual limbs may exacerbate damage to the underlying endothelial cells and initiate a cascade of potent mitogenic factors known to control the proliferation, differentiation, and function of osteoprogenitor cells. ${ }^{9}$ Given the synergistic relationship between angiogenesis and osteogenesis, ${ }^{10}$ and the influence of environmental conditions on bone formation, ${ }^{9}$ hypoxic conditions from tourniquets may in part explain the high frequency of heterotopic ossification (HO) seen during OIF/OEF.

$\mathrm{HO}$ is a pathological process characterized by ectopic bone growth in musculature and/or periarticular regions and frequently manifests following tissue trauma, traumatic limb amputation, and brain/spinal-cord injury ${ }^{11-16}$ (Figure 1). The occurrence of HO following combat-related injury has been reported in the US military medical literature since the Civil War ${ }^{17}$ and World War I; ${ }^{18}$ however, OEF and OIF have been unique. The peer-reviewed literature has indicated that approximately $63 \%-65 \%$ of wounded service members with traumatic combat-related limb loss have experienced HO during OIF/OEF, ${ }^{11,19,20}$ a much higher frequency than in other military conflicts. Ectopic bone growth has been significantly correlated with the trauma mechanism, zone of injury, and postoperative negative-pressure treatment, ${ }^{21}$ but, to the author's knowledge, to date, no studies have examined the potential link between tourniquet use/duration and the potential manifestation of ectopic bone formation in combatinjured service members.

Assessing hypoxia-induced HO from tourniquet usage remains challenging, as it was not until July 2004 that the United States Army's Institute of Surgical Research issued a recommendation that every soldier carry a modern tourniquet. ${ }^{22}$ Additionally, correlating tourniquet-induced $\mathrm{HO}$ in previous military conflicts is not feasible, since poor medical documentation and inadequate application of these medical devices prevent large-scale meta-analyses. ${ }^{5}$ Therefore, this article focuses on the basics of bone biology and how tourniquet usage following combat trauma

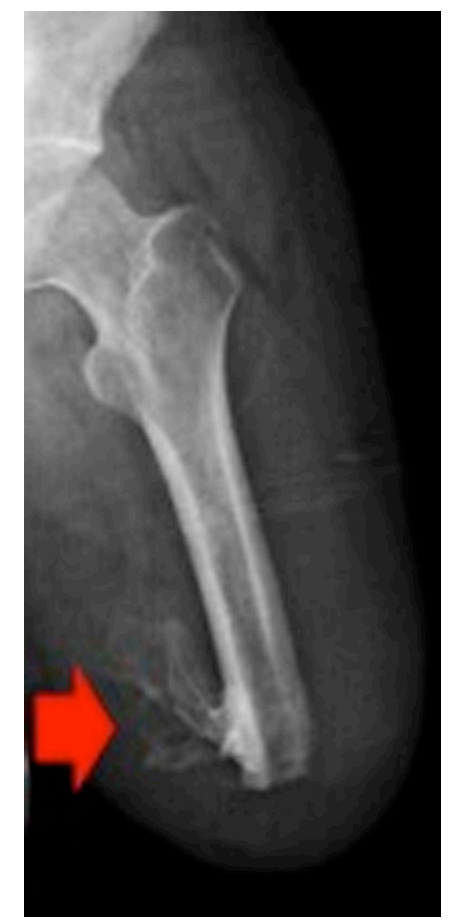

Figure I Radiographic image demonstrating heterotopic ossification within the residual limb of a combat-injured service member.

may impact osteogenesis, and subsequently, ectopic bone formation.

\section{Narrative}

Research has indicated that endothelial cells, which play a key role in angiogenesis, are of critical importance for bone formation, repair, and $\mathrm{HO}$ development. ${ }^{23}$ Impairment to the underlying endothelial cells from an oxygen-deprived microenvironment (as is the case with tourniquet usage) sets off a cascade of events once hypoxia-inducible factor-1 alpha (HIF-1 $\alpha$ ), an oxygen-sensitive proteolytic mechanism, becomes stabilized. ${ }^{10}$ HIF- $1 \alpha$ translocation from the cytoplasm to nucleus may initiate chemotactic agents, including upregulation of vascular endothelial growth factor (VEGF), transforming growth factor beta, fibroblast growth factor, and glucose transporters. ${ }^{24}$ In fact, overexpression of HIF-1 $\alpha$ through the selective deletion of the Von Hippel-Lindau gene in a small-animal model has demonstrated a significant increase in VEGF, which resulted in extremely dense, wellvascularized bones. ${ }^{24}$

Elevations in HIF- $1 \alpha$ and VEGF have been noted to directly influence blood-vessel invasion into ossification centers and are key to chondrocyte survival. ${ }^{25}$ For instance, HIF-1 $\alpha$ levels impact chondrocyte proliferation at the epiphyseal plate, ${ }^{10}$ an anatomical location renowned for having an alkaline $\mathrm{pH}$ and decreased oxygen content ${ }^{26}$ during skeletal 
growth and development. Decreased oxygen content and hypoxic conditions have also been linked with increases in alkaline phosphatase (AP) levels ${ }^{27}$ and HIF-2 $\alpha$, which may regulate RunX2, a master osteoblast factor necessary for differentiation. ${ }^{10}$ These observations may in part explain the rise in tourniquet-induced hypoxic $\mathrm{HO}$ formation, as Isaacson et al previously noted that ectopic bone formation occurred from endochondral ossification (Figure 2). ${ }^{13}$

The hypoxic conditions that transpire following tourniquet usage may also influence mesenchymal stem cell (MSC) function. In vitro experimentation with bone-marrow stromal cells has shown that MSC differentiation accelerated threefold in hypoxic versus normoxic conditions, ${ }^{27}$ while a separate study also indicated that a deoxygenated environment increases bone morphogenetic protein 2 messenger RNA expression 2.5-fold after only 2 hours. ${ }^{9}$ The importance of MSC function and its link with $\mathrm{HO}$ occurrence has previously been identified in wartraumatized muscle tissue..$^{28}$ In a study by Nesti et al, debrided muscle from soldiers sustaining traumatic open extremity injuries were harvested, enriched, expanded in culture, and exposed to induction media for osteogenesis, chondrogenesis, and adipogenesis. ${ }^{28}$ Genetic markers in the traumatized tissue demonstrated the potential of these cells to differentiate into multiple mesenchymal lineages. ${ }^{28}$ War-traumatized muscle tissue also exhibited a significant increase in AP activity, production of a mineralized bone matrix, and upregulation of osteoblast-associated gene $C B F A 1,{ }^{29}$ all of which are correlative factors for HO. Therefore, disruption of homeostatic MSC processes following tourniquet use may adversely mediate MSC differentiation through a similar mechanism as seen in war-traumatized soft tissues, with the mutual malefactor being extended peripheral hypoxia as a result of inadequate blood circulation.

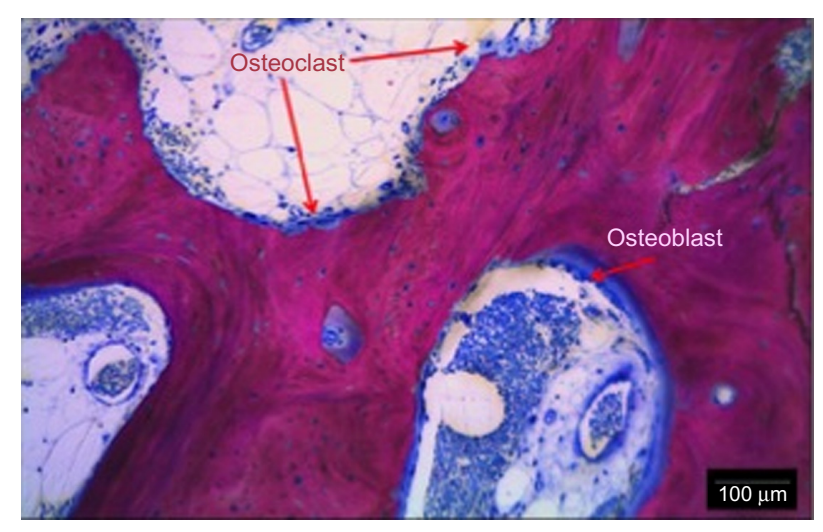

Figure 2 Heterotopic ossification bone sectioned, stained, and analyzed using light microscopy. Note the distinct regions of bone formation and resorption due to osteoblasts and osteoclasts.
Hypoxic environments and endothelial cell damage have been previously linked with ossification in two murine $\mathrm{HO}$ models; however, there remains a knowledge gap and translational concern between small-animal models and the clinical condition. In one study by Lounev et al, researchers isolated vascular endothelial and smooth-muscle cells to determine their respective contribution to stages of ectopic bone development. ${ }^{23}$ Cells expressing the vascular endothelial tissuespecific Tie2/Tek marker at some point in their development contributed heavily to the osteogenic stages of $\mathrm{HO}$, while the role of smooth-muscle cell lineages was negligible. ${ }^{23}$ The identification of endothelial-specific precursors suggests the tissue plays a critical role in the disease's progression and may be a cause for $\mathrm{HO}$ resulting from hypoxia-induced cellular damage.

Understanding the link between tourniquet use, persistent tissue hypoxia, and $\mathrm{HO}$ formation may improve the standard of care for wounded service members suffering combatrelated amputations. Persistent tissue hypoxia remains a frequent problem in the management of open wounds, as low oxygenation has been demonstrated to have deleterious effects on wound closure rates, latency to resumption of an unperturbed blood flow, and may delay the final stages of healing. ${ }^{30}$ Although there are several diagnostic measures available to determine the rate of hypoxia in localized tissue, none of the methods is without its faults and requires strict adherence to protocols to collect reliable data. Direct measurement, albeit the most accurate method, is generally avoided due to its invasiveness. ${ }^{31}$ Several imaging-derived techniques (positron emission tomography and magnetic resonance imaging scans) are primarily applicable to research rather than clinical applications due to their costliness and lengthy procedures; while other techniques such as duplex ultrasonography and arteriography are most helpful for mapping the revascularization of under-perfused tissue. . $^{31,32}$ New techniques like near-infrared spectroscopy and blood oxygen level-dependent magnetic resonance imaging may provide noninvasive, precise, and time-effective means to determining tissue hypoxia, but their outputs still require fine-tuning by developers before they can become clinically relevant diagnostic tools. ${ }^{31,33}$

\section{Future directions}

While this narrative provides plausible rationales as to why hypoxic environments, such as is the case with tourniquets, may be associated with the higher incidences of HO formation in our nation's service members during $\mathrm{OIF} / \mathrm{OEF} / \mathrm{OND}$, further empirical evidence is required to fully understand the 
etiology of HO. The next steps for assessing the link between tourniquet duration, tissue hypoxia, and $\mathrm{HO}$ formation may include conducting simulated blast-related ovine models (rather than small murine studies), since the mineral apposition rate of bone in these animals more closely matches that of human bone. ${ }^{34}$ Improved diagnostic techniques are also required to better understand hypoxic tissue pathology independent of tourniquet use. ${ }^{31,33}$ By further developing these preclinical models, researchers may begin to bridge the current knowledge gap in HO research.

\section{Acknowledgments}

This material is based upon work supported by the United States Department of the Army under Award Numbers W81XWH-12-2-0017 to the Henry M Jackson Foundation for the Advancement of Military Medicine, Inc. (Fort Detrick, MD, USA) and NF90UG to the Center for Rehabilitation Science Research (Bethesda, MD, USA).

\section{Disclaimer}

The opinions or assertions contained herein are the private views of the authors and are not to be construed as official or as reflecting the views of the United States Department of the Army, the United States Department of Defense, or the US Government.

\section{Disclosure}

The authors declare that they have no conflicts of interest in this work.

\section{References}

1. Isaacson BM, Weeks SR, Pasquina PF, Webster JB, Beck JP, Bloebaum RD. The road to recovery and rehabilitation for injured service members with limb loss: a focus on Iraq and Afghanistan. US Army Med Dep J. Jul-Sep 2010:31-36.

2. Fisher H. A Guide to U.S. Military Casualty Statistics: Operation New Dawn, Operation Iraqi Freedom, and Operation Enduring Freedom. Available from: http://www.fas.org/sgp/crs/natsec/RS22452.pdf. Accessed February 27, 2014.

3. Covey DC. Combat orthopaedics: a view from the trenches. J Am Acad Orthop Surg. 2006;14(10 Spec No):S10-S17.

4. Walters TJ, Wenke JC, Kauvar DS, et al. Laboratory evaluation of battlefield tourniquets in human volunteers. US Army Med Dep J. Apr-Jun 2005:50-57.

5. Richey SL. Tourniquets for the control of traumatic hemorrhage: a review of the literature. World J Emerg Surg. 2007;2:28.

6. Walters TJ, Mabry RL. Issues related to the use of tourniquets on the battlefield. Mil Med. 2005;170(9):770-775.

7. Lakstein D, Blumenfeld A, Sokolov T, et al. Tourniquets for hemorrhage control on the battlefield: a 4-year accumulated experience. J Trauma. 2003;54(Supp1 5):S221-S225.

8. Clarke MT, Longstaff L, Edwards D, Rushton N. Tourniquet-induced wound hypoxia after total knee replacement. J Bone Joint Surg Br. 2001;83(1):40-44.
9. Bouletreau PJ, Warren SM, Spector JA, et al. Hypoxia and VEGF up-regulate BMP-2 mRNA and protein expression in microvascular endothelial cells: implications for fracture healing. Plast Reconstr Surg. 2002;109(7):2384-2397.

10. Riddle RC, Khatri R, Schipani E, Clemens TL. Role of hypoxiainducible factor-1alpha in angiogenic-osteogenic coupling. J Mol Med (Berl). 2009;87(6):583-590.

11. Potter BK, Burns TC, Lacap AP, Granville RR, Gajewski DA. Heterotopic ossification following traumatic and combat-related amputations. Prevalence, risk factors, and preliminary results of excision. J Bone Joint Surg Am. 2007;89(3):476-486.

12. Potter BK, Forsberg JA, Davis TA, et al. Heterotopic ossification following combat-related trauma. J Bone Joint Surg Am. 2010; 92 Suppl 2:74-89.

13. Isaacson BM, Brown AA, Brunker LB, Higgins TF, Bloebaum RD. Clarifying the structure and bone mineral content of heterotopic ossification. J Surg Res. 2011;167(2):e163-e170.

14. Shehab D, Elgazzar AH, Collier BD. Heterotopic ossification. J Nucl Med. 2002;43(3):346-353.

15. Isaacson BM, Weeks SR, Potter BK, Pasquina P, Bloebaum RD. Relationship between volumetric measurements of heterotopic ossification in wounded service members and clinically available screening tools. J Prosthet Orthot. 2012;JPO 24-3B:138-143.

16. IsaacsonBM, StinstraJG, MacLeodRS, Pasquina PF, BloebaumRD. Developing a quantitative measurement system for assessing heterotopic ossification and monitoring the bioelectric metrics from electrically induced osseointegration in the residual limb of service members. Annals of Biomedical Engineering. 2010;38:2968-2978.

17. Otis GA, Huntington DL. Wounds and complications. In: Barnes JK, editor. The Medical and Surgical History of the War of the Rebellion. Part 3, Vol 2, Surgical History. Washington DC: Government Printing Office; 1883:880.

18. Brackett EG. Care of the amputated in the United States. In: Ireland MW, editor. The Medical Department of the United States Army in the World War. Vol 11. Part 1. Washington DC: Government Printing Office; 1927:713-748.

19. Forsberg JA, Pepek JM, Wagner S, et al. Heterotopic ossification in high-energy wartime extremity injuries: prevalence and risk factors. J Bone Joint Surg Am. 2009;91(5):1084-1091.

20. Forsberg JA, Potter BK. Heterotopic ossification in wartime wounds. J Surg Orthop Adv. 2010;19(1):54-61.

21. Brown KV, Dharm-Datta S, Potter BK, et al. Comparison of development of heterotopic ossification in injured US and UK Armed Services personnel with combat-related amputations: preliminary findings and hypotheses regarding causality. J Trauma. 2010; 69 Suppl 1:S116-S122.

22. Little R. US military widening use of tourniquets. Baltimore Sun. May 2, 2005. Available from: http://www.baltimoresun.com/news/bal-te. tourniquets02may02,0,1361397.story. Accessed January 15, 2014.

23. Lounev VY, Ramachandran R, Wosczyna MN, et al. Identification of progenitor cells that contribute to heterotopic skeletogenesis. J Bone Joint Surg Am. 2009;91(3):652-663.

24. Wang Y, Wan C, Deng L, et al. The hypoxia-inducible factor alpha pathway couples angiogenesis to osteogenesis during skeletal development. J Clin Invest. 2007;117(6):1616-1626.

25. Zelzer E, Mamluk R, Ferrara N, Johnson RS, Schipani E, Olsen BR. VEGFA is necessary for chondrocyte survival during bone development. Development. 2004;131(9):2161-2171.

26. Brighton CT, Adler S, Black J, Itada N, Friedenberg ZB. Cathodic oxygen consumption and electrically induced osteogenesis. Clin Orthop Relat Res. 1975;(107):277-282.

27. Ren H, Cao Y, Zhao Q, et al. Proliferation and differentiation of bone marrow stromal cells under hypoxic conditions. Biochem Biophys Res Commun. 2006;347(1):12-21.

28. Nesti LJ, Jackson WM, Shanti RM, et al. Differentiation potential of multipotent progenitor cells derived from war-traumatized muscle tissue. J Bone Joint Surg Am. 2008;90(11):2390-2398. 
29. Jackson WM, Aragon AB, Bulken-Hoover JD, Nesti LJ, Tuan RS. Putative heterotopic ossification progenitor cells derived from traumatized muscle. J Orthop Res. 2009;27(12):1645-1651.

30. Kivisaari J, Niinikoski J. Effects of hyperbaric oxygenation and prolonged hypoxia on the healing of open wounds. Acta Chir Scand. 1975;141(1):14-19.

31. Mathieu D, Mani R. A review of the clinical significance of tissue hypoxia measurements in lower extremity wound management. Int $J$ Low Extrem Wounds. 2007;6(4):273-283.
32. Wimberley PD, Grønlund Pedersen K, Olsson J, Siggaard-Andersen O. Transcutaneous carbon dioxide and oxygen tension measured at different temperatures in healthy adults. Clin Chem. 1985;31(10):1611-1615.

33. Stefanovska A. Dynamics of blood oxygenation gives better insight into tissue hypoxia than averaged values. Am J Physiol Heart Circ Physiol. 2009;296(5):H1224-H1226.

34. Bloebaum RD, Willie BM, Mitchell BS, Hofmann AA. Relationship between bone ingrowth, mineral apposition rate, and osteoblast activity. J Biomed Mater Res A. 2007;81(2):505-514.

\section{Publish your work in this journal}

Orthopedic Research and Reviews is an international, peer-reviewed, open access journal focusing on the patho-physiology of the musculoskeletal system, trauma, surgery and other corrective interventions to restore mobility and function. Advances in new technologies, materials, techniques and pharmacological agents are particularly welcome. The journal welcomes

\section{Dovepress}

original research, clinical studies, reviews \& evaluations, expert opinion and commentary, case reports and extended reports. The manuscript management system is completely online and includes a very quick and fair peer-review system, which is all easy to use. Visit http://www.dovepress. com/testimonials.php to read real quotes from published authors.

Submit your manuscript here: http://www.dovepress.com/orthopedic-research-and-reviews-journal 